\title{
Assessment of Pain Intensity among Preschool-age Children during Venipuncture
}

\author{
1Yahia Mohamed Sayed; 2 Soheir Abd-Rabou Mohamed; 3 Nagat Farouk Abolwafa
}

1. Master degree in Pediatric Nursing Faculty of Nursing, Minia University

2. Professor of Pediatric Nursing, Faculty of Nursing -Cairo University

3. Lecturer of Pediatric Nursing Faculty of Nursing - Minia University

\begin{abstract}
Background: Venipuncture is a devastating medical, emotional, and physical problem for pediatric patients and their families. Blood drawing is one of the most frightening and distressing nursing procedures for hospitalized children. Aim: To assess pain intensity among preschool children during venipuncture. Research design: A descriptive research design was used in the current study. Sample included 60 preschool-age children undergoing venipuncture procedures over six months. Setting of the study: - Pediatric medical unit at Minia University Hospital for Obstetrics and Pediatrics. Tools: Tool (I): structured interview questionnaire which developed by the researcher Tool (II): Wong-Baker Faces Pain Rating Scale Tool (III): Children's Hospital of Eastern Ontario Pain Scale (CHEOPS). Results: The highest percentage of the studied preschool-age children experienced severe pain during venipuncture procedure according Wong-Baker Faces Pain Rating Scale. The total mean scores of Wong-Baker Faces Pain Rating Scale and Children's Hospital of Eastern Ontario Pain Scale were high markedly during venipuncture. There were statistically significant negative correlations between children's age and the total mean scores of the CHEOPS and Face Pain Rating Scale during venipuncture. Conclusion: it was concluded that preschool-age children complained from severe pain intensity during venipuncture procedure. Recommendation: An educational training program is mandatory for pediatric nurses about pain assessment and pain management strategy during venipuncture and other painful procedures.
\end{abstract}

Keywords: venipuncture, preschool-age children, pain intensity

\section{Introduction}

Children are not outlandish with pain; in fact, it is a part of their lives. They experience it during vaccination and venipuncture in the early days of their births and even common diseases in their childhood. Irrespective of this universality of pain, it is yet a complex and multidimensional experience that is hard to clearly define and even more troubling when trying to understand what pain is among children (Ebrahimpour, Pashaeypoor, Salisu, Cheraghi\&Hosseini, 2019).

According to Becker, Navratilova, Nees, and Van Damme (2018), and the International Association of the Study of Pain [IASP] (2020), pain is much more than the conscious perception of a sensory event. It is aversive and inseparably linked to emotion as reflected in the generally accepted definition of pain as "an unpleasant sensory and emotional experience associated with actual or potential tissue damage, or described in terms of such damage".

Emerging evidence from a recent study by Levy and Mills (2018) emphasized that pain is considered the fifth vital sign. In the same context, Pancekauskaitè and Jankauskaitè (2018) pointed out that pediatric pain and its assessment and management are challenging for health care professionals. Pediatric procedural pain is often underestimated and neglected because of various myths, beliefs, and difficulties in its evaluation and treatment. It is known that neonates and children can feel pain and that it has long-term effects that last through childhood into adulthood.

Pain is a substantial source of distress for hospitalized children, family caregivers, and healthcare providers alike. Pain in children can be produced from physical damage, disease process, invasive procedures, and other unknown factors (Amponsah et al., 2020). Several previous studies have shown that children's common source of pain comes from medical procedures and nursing, such as immunization and venipuncture (Thrane, Wanless, Cohen P a g e | 56
\&Danford, 2016). Uncontrolled pain also has a direct impact on health outcomes and more than a few effects on all areas of life (Kahsay, 2017).

Venipuncture is a recurrently performed needlerelated procedure, is one of the most alarming experiences and a common source of moderate to severe pain among children. Venipuncture is a devastating medical, emotional, and physical problem for both pediatric patients and their families (Walther-Larsen et al., 2017). Painful, invasive procedures are disturbing - for many children, worse than the disease itself. The seemingly endless barrage of needle sticks frightens children and tears at the heart of parents, who are unable to guard their children against them. One can assume that the prick of a needle will hurt anyone, it is quite clear that there are significant differences between children in how they respond to noxious stimuli (Karlsson, Rydstrom, Enskar\&Englund, 2014).

Meentken, Beynum, Legerstee, Helbing and Utens, (2017) documented that hospitalized children undergo multiple, cyclic procedures such as venipuncture throughout their treatment course, and many describe such procedures as the most distressing part of their hospitalization. Management of pain is a basic need and precise of all children; effective pain management requires health professionals, including pediatric nurses, is eager to try many interventions to achieve optimal results.

Bukola and Paula, (2017); El Geziry, Toble, Al Kadhi, Pervaiz, and Al Nobani, (2018) emphasized that unrelieved continuing pain may have untoward effects on children's health, functional abilities, and quality of life. Appropriately managing the pain from vein punctures is associated with shorter hospital stays and lower hospital costs. Freedom from pain is the right of children and must be considered in nursing practice. Pain-reducing methods are grouped into two categories pharmacological and nonpharmacological interventions or both (as integrative

Yahia M., et al 
medicine). Non-pharmacological measures categorized into biophysical interventions like massage, acupuncture, and transcutaneous electrical nerve stimulation (TENS), and heat and cold therapy, behavioral-cognitive strategies such as distraction, relaxation, play, guided imagery, therapeutic touch, biofeedback, thought stopping, positive self-talk. Alotaibi, Higgins, Day and Chan, (2018) documented that the mitigation of suffering is one of the four fundamentals of nursing care. The pain must be detected before it can be alleviated, and the assessment of pain is an essential part of nurses' responsibilities.

\section{Significance of the Study}

Despite the up warding evidence on pain management and the accessibility of evidence-based clinical guidelines, pain in children is still inadequately treated. This can be attributed to a lack of knowledge among health professionals, misconceptions among children and their families, or lack of guidelines (Thrane et al., 2016).

Through empirical observations and experiences as a clinical instructor in the pediatric care units, it was noticed that many children who are scheduled for venipuncture for blood sampling are exposed to varying intensity of pain. Based on the literature review, preschool-age children were selected to participate in the current study because they are among the most affected age groups in the hospital. They have worries about the anticipation of the painful procedures, fear of bodily injury from mutilation, bodily intrusion, body image changes, disability, or even death. As well they perceive painful procedure as a punishment for misdeeds.

Effective procedural pain management is essential to ensure adherence to the increased number of painful procedures required for health maintenance in pediatric patients and to create a cooperative and trusting relationship between health care providers, children, and their families. Finally, most pain can be either prevented, treated, or at least reduced using inexpensive techniques. Despite this, most children in our hospitals do not receive adequate treatment. Thus; the aim of the current study was to assess pain intensity among preschool children during venipuncture. Ultimately, the results of the current study might generate attention and motivation and evidence-base for further researches in the field of pediatric pain as well as providing guidance and recommendations that should be reflected in pediatric nursing education and practice.

\section{Aim of the Study}

The aim of the current study was to assess pain intensity among preschool children during venipuncture

\section{Research question: -}

- What is the level of pain intensity among preschoolage children during venipuncture?

- What are the factors affecting the level of pain intensity among preschool-age children during venipuncture?

\section{Research design: -}

A descriptive research design was utilized to achieve the aim of the current study. Descriptive research seeks to provide an accurate description of observations of phenomena (Grove \& Gray, 2018). This design helps describe a situation or an event in knowing the level of pain intensity among preschool-age children during venipuncture.

\section{Sample: -}

The study sample consisted of all available preschool-age children undergoing venipuncture procedures over six months (the total number was 60 children) who admitted to the pediatric medical unit at Minia University Hospital for Obstetrics and Pediatrics (MUHOP).

\section{Inclusion criteria:}

- Children aged 3-6 years.

- Children exposing to peripheral venipuncture (blood sampling) without interventions to decrease pain during puncture.

\section{Setting: -}

The current study was conducted in the pediatric medical unit on the fourth floor at Minia University Hospital for Obstetric and Pediatric (MUHOP).

\section{Data Collection Tools: \\ The following three tools were used to collect the required data: -}

Tool I: A structured interview questionnaire in the Arabic language was designed by the researcher after reviewing the related literature and consists of 19 questions. It divided into two parts:

Part 1: - Personal and social characteristics of children as age, gender, rank, place of residence, mothers' age, and occupation. Part 2: - It involved 13 questions, five questions related to the child's medical history, such as diagnosis, history of previous hospitalization, causes, and the number of prior hospitalization admissions. Also, it comprised five questions about past painful experiences that the child exposed to it. The mothers of children have answered these questions as previous painful events, factors that increase the child's pain, factors that decrease the child's pain, and the sites of the past pain. This part included three questions related to the venipuncture site, such as the site of venipuncture, numbers of vein penetration, and the place where the venipuncture took place.

Tool II: - Wong-Baker Faces Pain Rating Scale, developed by Wong and Baker (1983). It was a self-report pain scale to assess pain intensity in children aged 3 to 7 years. Each child was asked to choose the face that best described the intensity of the pain being experienced. Each face was rated by number to determine the intensity of pain, which $(0-10)$ coding as the following: (Face $0=$ No hurt, Face $2=$ Hurts a little bit, Face $4=$ Hurts a little more, Face $6=$ Hurts, even more, Face $8=$ Hurt whole lot and Face $10=$ Hurts worst). These faces were assigned scores from 0 to 10 , with a higher score indicating a higher severity of pain. According to a study in the Kingdom of Saudi Arabia, conducted by Alalo, Ahmad, and El Sayed (2016) to identify pain intensity after an ice pack application prior to venipuncture among 50 school-age children that modify the scoring system of Wong-Baker Faces Pain Rating Scale to become score 0 referred to no pain, score two referred to mild pain, score 4-6 referred to moderate pain and score 810 referred to sever pain. Apart from being acceptable and straightforward, this scale had a high test-retest reliability and content validity. The scale had high reliability with a Cronbach's alpha coefficient of 0.70 , as tested by Drendel, Kelly, and Ali (2011). The scale is available online without copyright restrictions. 
Tool III: - The Children's Hospital of Eastern Ontario Pain Scale (CHEOPS): Developed by McGrath et al. (1985). The scale can be used to monitor the effectiveness of interventions for reducing pain and discomfort. A behavioral observation scale will be used to rate a child's intensity of pain on six verbal and motor behaviors. Each behavior was assigned a value according to the following criteria, 0 (behavior that is the antithesis of pain), 1 (behavior that not indicative of pain, but not the antithesis of pain), two behavior indicating mild to moderate pain), and 3 (behavior indicative of severe pain). The total score for the tool ranges from 4-13; a score higher than 4 indicates pain. Concerning the reliability of the scale, Suraseranivongse et al. (2001) tested the scale reliability and it was 0.80 , which was considered acceptable. CHEOPS is available online without copyright restrictions.

\section{Validity:}

The content validity of the data collection tool (1) was examined by three experts who were affiliated to the Faculty of Nursing, Minia, and Assuit University at the Pediatric Nursing Department. The tool was examined for content coverage, clarity, relevance, applicability, wording. Based on experts' comments and recommendations, minor modifications had been made, such as rephrasing and rearrangements of some sentences.

\section{Pilot Study: -}

The pilot study was conducted on six children who met the inclusion criteria to investigate and ensure the feasibility, objectivity, applicability, clarity, and adequacy, and to determine possible problems in the methodological approach or tools. The results of the pilot study were used to test the proposed statistical and data analysis methods. The tools were completed without difficulty. Children who participated in the pilot study were included in the total sample of the current study.

\section{Ethical Considerations:}

Written approval was obtained from the Research Ethics Committee at the Faculty of Nursing, Minia University. Written permission was granted from the director of MUHOP and the chairpersons of the pediatric medical units after explaining the aim and nature of the study. The written informed consent was obtained from the mothers of children after a complete description of the study's aim and nature to gain their acceptance and cooperation. Children and their mothers were informed that contribution to the study was voluntary. The researcher also informed the mothers and preschool children about their rights to withdraw from the study at any time without giving any cause and without any effect on the care of their children. Confidentiality was secured for each mother and her child, where they assured that the study was harmless, and all the gathered data used for the research purpose only.

\section{Procedure}

Before the venipuncture procedure: -

The researcher gave the mothers and their children a clear and simple explanation of the aim and the content of the sheet; reassuring them that the procedure is safe, and invited them to participate and written informed consent was obtained from mothers. The researcher interviewed the children and their mothers individually to collect data related to the characteristics of children who met the inclusion criteria using (tool 1) the interview took place in the beside area of the medical unit where venipuncture for blood samples taken. After explaining the purpose and during the interview the researcher explained the first pain assessment scales (WongBaker Faces Pain Rating Scale) and the second pain scale (CHEOPS) taught each child about how to use the scale. The time for the interview took about 30-35 minutes for each child. The procedure was discussed with the responsible nurse to gain her cooperation and to save time and effort

\section{During venipuncture: -}

Only a usual venipuncture done by the assigned nurse based on physician written order. During the venipuncture procedure, the researcher assessed and documented the child's pain intensity using the behavioral observation scale (CHEOPS). Immediately after the venipuncture, each child was asked to choose the face that describes his intensity of pain based on Wong-Baker Faces Pain Rating Scale. Data collection was conducted over 6 months extending from March 2019 till August 2019.

\section{Statistical Analysis}

The collected data was coded, categorized, tabulated, and analyzed using the Statistical Package for Social Science (SPSS 20.0). Descriptive statistics in the form of frequencies, percentages for the qualitative variables, mean and standard deviation for the quantitative variables was used. Chi square was used to test the association between two Qualitative variables. Spearman's rank correlation was used to assess the interrelationships among the quantitative variables. Graphs were done for data visualization using Microsoft Excel. The P - value of $\leq 0.05$ indicates a significant result while, $P$ value of $>0.05$ indicates a non-significant result.

\section{Results:}

Table (1): Percentage Distribution of the Studied Children According to Their Personal and Social Data (n=60).

\begin{tabular}{|l|c|c|}
\hline \multicolumn{1}{|c|}{ Personal and social data } & No. \\
\hline Age / years:- & 10 & 16.7 \\
\hline $3-<4$ & 18 & 30.0 \\
\hline $4-<5$ & 22 & 36.6 \\
\hline $5-<6$ & 10 & 16.7 \\
\hline 6 & \multicolumn{2}{|c|}{$4.6 \pm .9$ years } \\
\hline Mean - SD & 36 & 60.0 \\
\hline Gender:- & 24 & 40.0 \\
\hline Male & 22 & 36.7 \\
\hline Female & 26 & 43.3 \\
\hline The child rank within the family:- & \\
\hline First & \multicolumn{2}{|l|}{} \\
\hline Second &
\end{tabular}


Minia Scientific Nursing Journal (Print - ISSN 2537-012X) (Online - ISSN 2785-9797) Vol. (8) No. (1) December 2020

\begin{tabular}{|l|c|c|}
\hline Personal and social data & No. & \% \\
\hline Third & 8 & 13.3 \\
\hline Fourth or more & 4 & 6.7 \\
\hline Mother educational level:- & \multicolumn{2}{|c|}{} \\
\hline Not read and write & 42 & 70.0 \\
\hline Basic education & 15 & 25.0 \\
\hline University & 5.0 \\
\hline Mother job:- & \multicolumn{2}{|l}{} \\
\hline Housewife & 51 & 85.0 \\
\hline Working outside house & 9 & 15.0 \\
\hline Place of Residence:- & 40 & 66.7 \\
\hline Rural & 20 & 33.3 \\
\hline Urban & \multicolumn{2}{|l}{} \\
\hline
\end{tabular}

Table (1) presented the personal data pertinent to children and their mothers who participated in the current study. More than one-third (36.6\%) of children's age ranged from $5<6$ years, and their mean age was $4.6 \pm .9$ years. Besides, $43.3 \%$ of them ranked as the second child, $60 \%$ were male, and $40 \%$ were female. The highest percentage $(70 \%)$ of the mothers was not read and write, and $85.0 \%$ of them were housewives.

Table (2): Percentage Distribution of the Studied Children According to Their Medical History (N=60).

\begin{tabular}{|c|c|c|}
\hline Child illness history & No. & $\%$ \\
\hline \multicolumn{3}{|l|}{ Child's diagnosis: } \\
\hline Pneumonia & 10 & 16.7 \\
\hline Diarrhea, vomiting and dehydration & 22 & 36.7 \\
\hline Favism & 3 & 5 \\
\hline Post streptococcal glomernepheritis & 7 & 11.7 \\
\hline Nephrotic syndrome & 6 & 10 \\
\hline Diabetes mellitus & 12 & 20 \\
\hline \multicolumn{3}{|l|}{ Type of the disease:- } \\
\hline Acute & 48 & 80 \\
\hline Chronic & 12 & 20 \\
\hline \multicolumn{3}{|l|}{ Previous hospital admission:- } \\
\hline Yes & 33 & 55 \\
\hline No & 27 & 45 \\
\hline \multicolumn{3}{|c|}{ If yes how many times of admission to hospital $(n=33)$ : } \\
\hline 1 & 17 & 51.5 \\
\hline 2 & 14 & 42.4 \\
\hline 3 & 2 & 6.1 \\
\hline Mean \pm SD & \multicolumn{2}{|c|}{$1.5 \pm .6$} \\
\hline \multicolumn{3}{|l|}{ Reason for admission $(n=33)$ :- } \\
\hline Emergency & 27 & 81.8 \\
\hline Follow up & 1 & 3 \\
\hline Medical condition & 5 & 15.2 \\
\hline
\end{tabular}

Table (2) pointed out that $36.7 \%$ of the studied children diagnosed with diarrhea, vomiting, and dehydration, followed by diabetes $(20 \%)$. The majority $(80 \%)$ of the studies children had acute health problems. More than half (55\%) of children had previous hospital admissions, and $51.5 \%$ were admitted to the hospital for the first time. The mean of prior hospital admission was $1.5 \pm .6$ times, and $81.8 \%$ from children admitted at the hospital for an emergency health problem.

Table (3): Percentage Distribution of the Studied Children According to Their Previous Painful Experience (n=60).

\begin{tabular}{|c|c|c|}
\hline \begin{tabular}{|c|} 
Previous history of pain \\
\end{tabular} & No. & $\%$ \\
\hline \multicolumn{3}{|l|}{ Previous painful experience: } \\
\hline Yes & 60 & 100 \\
\hline No & 0 & 0 \\
\hline \multicolumn{3}{|c|}{ If yes, most site of pain in the previous time:- \# } \\
\hline Abdominal pain & 48 & 80 \\
\hline Chest pain & 4 & 6.7 \\
\hline Bone pain & 8 & 13.3 \\
\hline Teeth pain & 42 & 70 \\
\hline NET pain & 42 & 70 \\
\hline Headache & 25 & 41.7 \\
\hline \multicolumn{3}{|c|}{$\begin{array}{l}\text { If yes, in the home what is the most measures to decrease pain } \\
\text { sensation:-\# }\end{array}$} \\
\hline Go to Sleep and Rest & 55 & 91.7 \\
\hline Taking Shower & 5 & 8.3 \\
\hline Playing with friends & 25 & 41.7 \\
\hline Using Analgesics & 36 & 60 \\
\hline \multicolumn{3}{|l|}{ Best position feels comfortable:- \# } \\
\hline Abdomen & 14 & 23.3 \\
\hline Back & 21 & 35 \\
\hline On side & 1 & 1.7 \\
\hline Semi-sitting & 25 & 41.7 \\
\hline Sitting & 2 & 3.3 \\
\hline
\end{tabular}




\section{\# More than one answer was responded}

\begin{tabular}{|l|c|c|}
\hline \multicolumn{1}{|c|}{ Previous history of pain } & No. & \% \\
\hline Presence of mother & 60 & 100 \\
\hline Toys & 32 & 53.3 \\
\hline Transitional objects & 20 & 33.3 \\
\hline Play with children & 33 & 55 \\
\hline
\end{tabular}

Table (3) revealed that all (100\%) of the studied children had previous painful experiences, and $80 \%$ of them suffered from abdominal pain. The majority of children (91.7\%) went to sleep and rest as home measures to relieve their pain, and $41.7 \%$ of them felt comfort in a semi-sitting position. The mother's presence and playing with other children were the main things that reduced pain in the hospital, as replied by $100 \%$ and $55 \%$ respectively of the studied children.

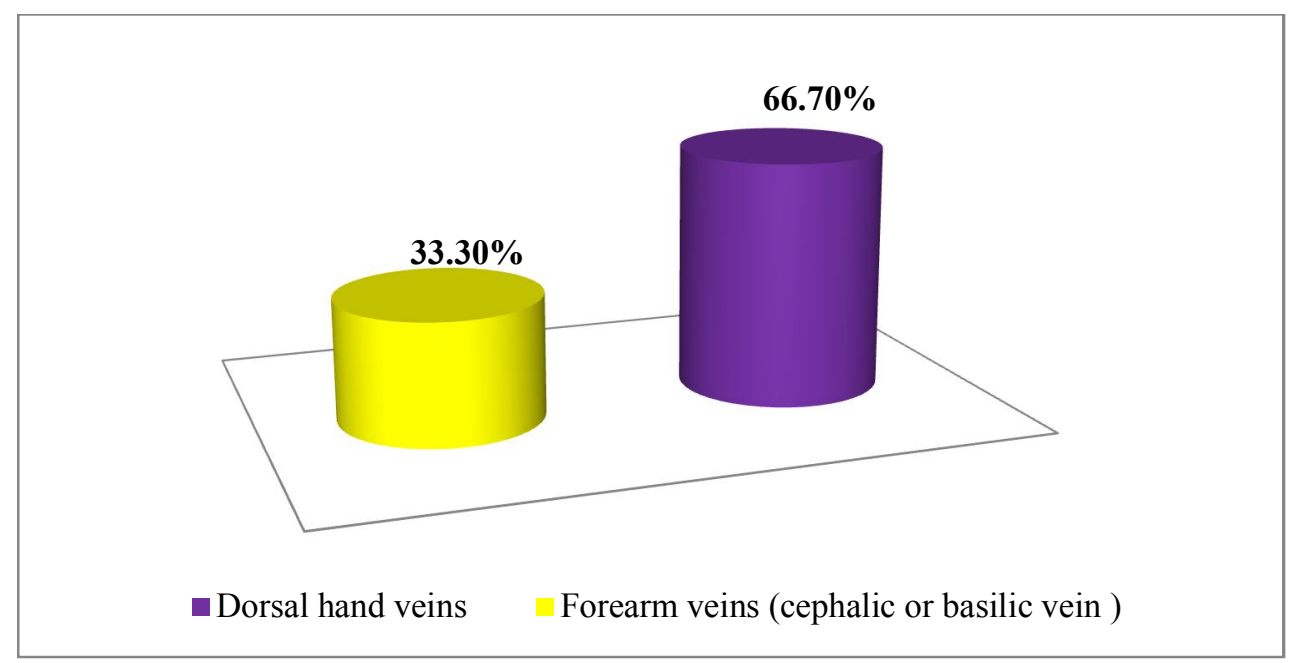

Figure (1): Percentage Distribution of Venipuncture Site among the Studied Children (n=60)

Figure (1) demonstrated that $66.7 \%$ of children had venipuncture in the dorsal hand veins whereas $33.3 \%$ had venipuncture in the forearm veins.

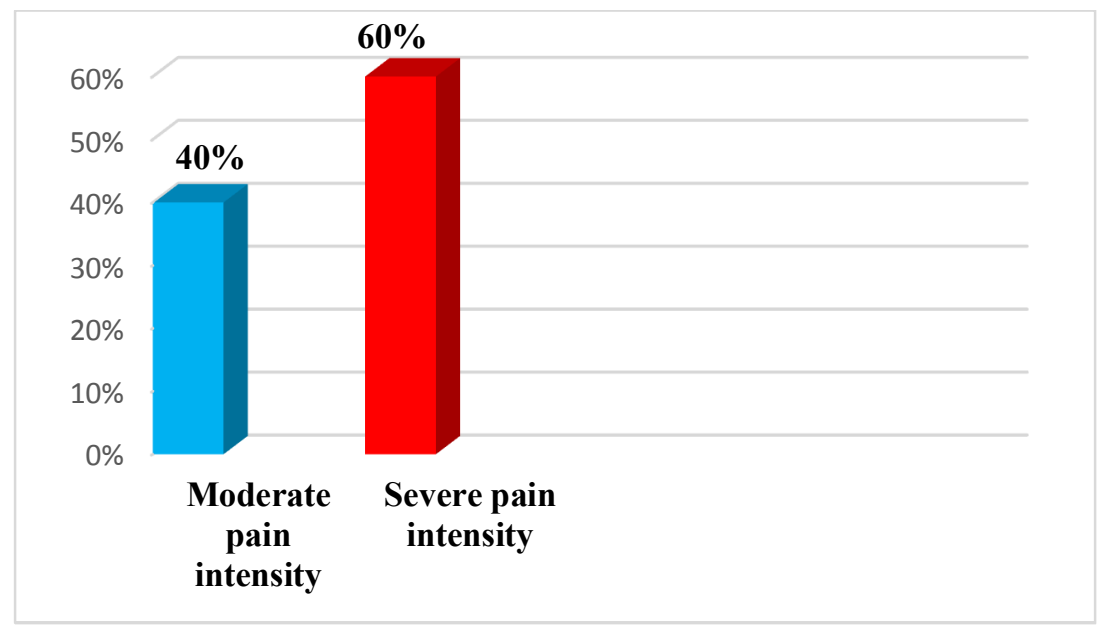

Figure (2): Pain Intensity during Venipuncture among the Studied Children According to Wong-Baker Faces Pain Rating Scale $(\mathbf{n}=60)$

Figure (2) showed that the highest percentage $(60 \%)$ of the children suffering from severe pain intensity during the venipuncture while $40 \%$. of them suffering from moderate pain intensity during the venipuncture according to Wong-Baker Faces Pain Rating Scale.

Table (4): Children's Hospital of Eastern Ontario Pain Scale among the Studied Children during Venipuncture (n=60).

\begin{tabular}{|ll|c|c|}
\hline CHEOPS & No. & $\mathbf{\%}$ \\
\hline Cry: & No cry & 0 & 0 \\
- & Moaning & 30 & 50.0 \\
- & Silent crying & 3 & 5.0 \\
- & Scream & 27 & 45.0 \\
\hline- & & & \\
\hline Facial: & Smiling & 0 & 0 \\
- & Composed & 18 & 30.0 \\
\hline
\end{tabular}




\begin{tabular}{|c|c|c|c|}
\hline CHEOPS & & No. & $\%$ \\
\hline- & Grimace & 42 & 70.0 \\
\hline \multicolumn{4}{|l|}{ Verbal: } \\
\hline - & The child talks about positive things & 0 & 0 \\
\hline - & No complains & 0 & 0 \\
\hline - & Complaints the Child about pain & 25 & 41.7 \\
\hline - & Child complains about pain, and other things & 35 & 58.3 \\
\hline \multicolumn{4}{|l|}{ Torso: } \\
\hline - & Neutral & 0 & 0 \\
\hline - & Shifting & 5 & 8.3 \\
\hline - & Tense & 20 & 33.3 \\
\hline - & Shivering & 5 & 8.3 \\
\hline - & Upright & 4 & 6.7 \\
\hline- & Restrained & 26 & 43.3 \\
\hline \multicolumn{4}{|l|}{ Touch: } \\
\hline- & $\begin{array}{l}\text { Not touching } \\
\text { Reach }\end{array}$ & $\begin{array}{l}0 \\
6\end{array}$ & $\begin{array}{c}0 \\
10.0\end{array}$ \\
\hline - & Touch & 8 & 13.3 \\
\hline - & Grab & 18 & 30.0 \\
\hline - & Restricted & 26 & 43.3 \\
\hline - & Reach and grab & 2 & 3.3 \\
\hline \multicolumn{4}{|l|}{ Legs } \\
\hline - & Neutral & 0 & 0 \\
\hline - & Squirming/ kicking & 11 & 18.3 \\
\hline - & Drawn & 9 & 15.0 \\
\hline - & Standing (kneeling) & 24 & 40.0 \\
\hline- & Restrained & 16 & 26.7 \\
\hline
\end{tabular}

Table (4) demonstrated that $50 \%$ of the studied children reacted by moaning during venipuncture. Seventy percent of them showed face grimacing. Concerning the verbal items of CHEOPS, 58.3\% of the studied children complained about pain, and about other things. In relation to torso items of CHEOPS, $43.3 \%$ of children watched restrained. It was found that $43.3 \%$ of children their touch was restricted during venipuncture. Relating to the legs element of CHEOPS $40 \%$ of the studied preschool-age children their legs showed kneeling.

Table (5): Total Mean Score of Faces Pain Rating Scale and CHEOPS during Venipuncture among the Studied Children $(\mathbf{n}=60)$.

\begin{tabular}{|l|c|}
\hline \multicolumn{1}{|c|}{ Pain scales } & Total Mean Score \pm SD \\
\hline Wong-Baker Faces Pain Rating Scale. & $7.2 \pm 2.2$ \\
\hline CHEOPS & $12.2 \pm .75$ \\
\hline
\end{tabular}

Table (5) evident that the total mean score \pm SD of the faces pain rating scale among children during venipuncture was $7.2 \pm$ 2.2 while The total mean score \pm SD of CHEOPS among children was $12.2 \pm .75$.

Table (6): Correlational Matrix between Children's Age and the Total Mean Scores of CHEOPS, Wong-Baker Faces Pain Rating Scale during Venipuncture $(n=60)$.

\begin{tabular}{|l|l|c|c|c|}
\hline \multicolumn{2}{|c|}{ Items } & Child age & Total CHEOPS & Total Face scale \\
\hline \multirow{2}{*}{ Child age } & $\mathrm{R}$ & & & \\
\cline { 2 - 5 } & P- Value & & & \\
\hline \multirow{2}{*}{ Total CHEOPS } & $\mathrm{R}$ & $-.490-^{* *}$ & & \\
& P- Value & .000 & & \\
\hline \multirow{2}{*}{ Face scale } & $\mathrm{R}$ & $-.305-^{*}$ & $.758^{* *}$ & \\
\cline { 2 - 6 } & P- Value & .018 & .000 & \\
\hline
\end{tabular}

*Statistically significant differences

Table (6) illustrated that there were statistically significant negative correlations between children's age and the total mean score of the CHEOPS and Face Pain Rating Scale during venipuncture ( $\mathrm{r}=-.490, \mathrm{P}=<.0001 \& \mathrm{r}=-.30, \mathrm{P}=<0.05$ respectively), and the other personal data of the studied children has no effect of their intensity of pain during the venipuncture procedure.

\section{Discussion}

The aim of the current study was to assess pain intensity among preschool children during venipuncture. Regarding the studied children's characteristics, the current study results proved that more than one-third of their ages ranged from 5-6 years, and their mean age was 4.6 \pm .9 years. These results were supported by an Indian study carried out by Abishak (2017) who found that $40 \%$ of children's age ranged from 5-6 years, and their mean age was $4.3 \pm 1.09$ years.

The current study results revealed that $43.3 \%$ of the studied children ranked as the second child, similarly, in an Egyptian study held by El Said, Ouda, Mahmoud, and El-
Sadek (2017) and Ebrahem et al. (2019) to examine the effect of cryotherapy on pain intensity at puncture sites among 40 children undergoing hemodialysis. The study results confirmed that $42.5 \%$ of children ranked as the second child within their families. On the contrary, in a recent Egyptian study conducted by Ebrahem et al. (2019) to examine the effect of cryotherapy and balloon inflation on reducing venous cannulation pain among 45 children undergoing hemodialysis. It was found that the maximum percentage $(46.7 \%)$ of the studied children was ranked as the first child.

Regarding the gender of the studied children, the current study results showed that the highest percentage was 
males. These results were supported by a similar Egyptian study held by El Said et al. (2017), who found that $60 \%$ of the studied children were males. In the same respect, Abishak (2017) found that $73.3 \%$ of the children were males, while $26.7 \%$ were female. On the contrary, a study conducted by Alalo et al. (2016) carried out a study to identify pain intensity after an ice pack application prior to venipuncture among 50 school-age children. The study summarized that $52 \%$ of children were females, while $48 \%$ were males.

The current study results proved that more than half of the studied children came from rural areas. This result could be related to almost hospital referral of acute cases to MUHOP for better facilities and equipment and care for children with various types of diseases in the Minia governorate and surrounding rural and semi-urban areas. In the same context, the United Nations Educational, Scientific, and Cultural Organization [UNESCO] (2017) documented that the rural population was $57 \%$ of the total population worldwide. In the same line, Egypt Demographics Profile (2020) reported that the rural community was $57 \%$ of the total residents, and the rate of urbanization was $1.68 \%$ annual rate of change. In the same context, the results of an Egyptian study carried out by Elhalafawy, Bahgat, AbdElhafez, A., and Farag (2020) found that $80 \%$ of children came from rural areas.

Concerning the personal data related to the mothers of the studied children, the current study results proved that the mothers' highest percentage $(70 \%)$ were not read and write. This result reflected the lower literacy rates among mothers who participated in the current study. In the same line, the Egypt Demographics Profile (2017) assured that females' literacy rate was $65.5 \%$ compared to $63.5 \%$ in 2016 . Accordingly, governmental and non-governmental organizations' efforts should continue to focus on female education, particularly in Upper Egypt. Because low levels of literacy can hinder economic development in the current rapidly changing, technology-driven world, this will positively reflect the health care system as a whole and care provided for the sick child.

The current study results documented that more than one-third of children diagnosed as having diarrhea, vomiting, dehydration, and one-fifth of them have diabetes. The current study findings were in accordance with the World Health Organization (WHO) (2020), which documented that diarrheal disease is a chief reason for child mortality and morbidity worldwide. It typically results from contaminated food and water sources and is responsible for killing around 525000 children every year. Severe dehydration and fluid loss were the leading causes of diarrhea deaths.

A recent systematic review held by Patterson et al. (2019) documented that the incidence rates in diabetes in children were available for $45 \%$ of countries (ranging from $6 \%$ in the sub-Saharan Africa region to $77 \%$ in the European region). Worldwide annual incidence estimates were 98,200 $(128,900)$ new cases under 15-year (under 20 years) agegroups. Corresponding prevalence estimates were 600,900 $(1,110,100)$ existing cases. The prevalence estimates have decreased in sub-Saharan Africa because allowance has been made for increased mortality in those with diabetes.

Concerning the previous hospital admissions of the studied children, the current study results showed that more than half of the children had prior hospital admissions. This result was similar to a quasi-experimental study conducted in India by Roy (2019) to determine the local cold application's effect before venipuncture on pain-related responses among 50 children. The results of the study indicated that $76 \%$ of studied children had previous hospital admissions.

In relation to the previous pain experience of studied children, the current study results revealed that all studied children had previous painful experiences. This result was similar to a study done by Roy (2019), who summarized that $74 \%$ of studied children had previous painful experiences. The results of the current study documented that $80 \%$ of them suffered from abdominal pain. This result could be rationalized as acute abdominal pain is one of the most common complaints in children. The same explanation was mentioned by Brusaferro, Farinelli, Zenzeri, Cozzali, and Esposito (2018), who documented that abdominal pain, is one of the utmost common symptoms in children. The pain is often acute onset and may be due to several gastrointestinal (GI) or extra intestinal causes.

According to Santillanes and Claudius (2015), as in adults, the usual site for venipuncture in infants and children is the antecubital fossa. However, any reasonably accessible or easily visible peripheral vein may be used, such as those on the hands, feet, or scalp for a tiny infant. The current study results were in accordance with the above-mentioned empirical evidence and demonstrated that about two-thirds of children had venipuncture from dorsal hand veins, whereas the rest had venipuncture from forearm veins. These results are similar to the findings of the study conducted by Abishak (2017), who found that $60 \%$ of children metacarpal vein in dorsal hand was punctured while $40 \%$ of them basilic vein was punctured.

Concerning the pain intensity level during venipuncture site among the studied children related to WongBaker Faces Pain Rating Scale. The current study results showed that the highest percentage $(60 \%)$ of the children suffering from severe pain during venipuncture while $40 \mid \%$ of them had moderate pain. This result may indicate the suffering of these children during venipuncture procedure.

Consistent with the current study results of El Said et al. (2017) who found that more than two thirds $(72.5 \%)$ of children had severe pain during venipuncture at pre cryotherapy. A study done by Gaikwad, et al. (2017) was congruent with this result. They found that, the vast majority of them (93\%) experienced severe pain. The current study results are similar to the study's findings held by Aswathi (2015) to measure the effectiveness of local cold application on pain response during intravenous cannula insertion among children. The study findings concluded that the majority $(83.33 \%)$ of children experienced severe pain during venipuncture.

This study results evident that the total mean score of the Wong-Baker Faces Pain Rating scale among children during venipuncture site was 7.2 \pm 2.2 . Similarly, Elhalafawy et al. (2020) who found that the mean score of Wong-Baker Faces Pain score during fistula puncture was 7.266 and 5.667, respectively, in days 1 and 2 . These results are consistent with the results of the study conducted by Kurian (2019), who found that the total mean score of the faces pain rating scale among children during venipuncture was $8.26 \pm 1.36$. The results of the current study were supported with that obtained by Fathalla and Bayoumi (2018), who found that total mean score of the faces pain rating scale among children during venipuncture was $6.28 \pm .61$. In the same direction, El Said et al. (2017) found that the mean score of Wong-baker Faces Pain Rating Scale for studied children was $8.30 \pm 1.80$. 
Regarding total mean score of CHEOPS among preschool-age children during venipuncture. The results of the current study clarified that the total mean score of CHEOPS among preschool-age children during venipuncture was $12.2 \pm$ .75. This result may confirm that the studied children suffer from a great degree of pain during venipuncture procedure. A quasi-experimental Indian study conducted by Roy (2019) reported that the total mean score of CHEOPS among children during venipuncture was $9.92 \pm 2.23$.

The study of current results illustrated statistically significant negative correlations between children's age and the total mean score of the Face Pain Rating Scale during venipuncture $(\mathrm{r}=-.30, \mathrm{P}=<0.05$, respectively). These results could be interpreted as all studied children who exposed to the venipuncture procedure were exposed to a higher level of pain regardless their gender, rank, and place of residence except their age. These findings are in agreement with a study conducted by Alalo et al. (2016) found that a significant positive correlation was found between the pain intensity reported by children and their age during venipuncture procedure $(\mathrm{r}=0.549 \mathrm{P}=<0.05)$.

\section{Conclusion}

Based on the current study results, it was concluded that, the highest percentage of the studied preschool-age children suffering from severe pain during venipuncture. All studied children had previous painful experiences, and the majority of them suffered from abdominal pain. The presence of the mother and playing with other children were the main things that reducing children' pain in the hospital. The total mean scores of Wong-Baker Faces Pain Rating Scale and Children's Hospital of Eastern Ontario Pain Scale were markedly high during venipuncture. There were statistically significant negative correlations between children's age and the total mean score of the CHEOPS and Face Pain Rating Scale during venipuncture.

\section{Recommendations}

In light of the findings of the current study, the following recommendations were suggested: -

- As much as possible diagnostic evaluations should be coordinated and consolidated so that the number of needle sticks and pain during venipuncture can be minimized.

- An educational training program is mandatory for pediatric nurses about pain assessment and pain management strategy during venipuncture and other painful procedures.

- Illustrated Arabic booklet about pain assessment and management in children should be available in every pediatric health care unit.

- Further studies are needed to focus on pain assessment and pain management strategy among children undergoing venipuncture procedure.

\section{Acknowledgment:}

The authors are thankful for the great help and cooperation received from the preschool children and their mothers. Great thanks to the all staff members of the pediatric medicine unit, at Minia University Hospital for Obstetric and Pediatric, for their support and cooperation to accomplish this study.

\section{References}

(1) Abishak, R. (2017). Effectiveness of cryotherapy for 15 seconds versus 30 seconds on pain during venipuncture among children in the pediatric ward, Government Rajaji Hospital, Madurai (Unpublished Doctoral dissertation, College of Nursing, Madurai Medical College, Madurai).

(2) Alalo, F. M. A., Ahmad, A. E. S., \& El Sayed, H. M. N. (2016). Pain intensity after an ice pack application prior to venipuncture among school-age children: an experimental study. Journal of Education and Practice; 7(36): 16-25.

(3) Alotaibi, K., Higgins, I., Day, J., \& Chan, S. (2018). Pediatric pain management: knowledge, attitudes, barriers and facilitators among nurses-integrative review. International Nursing Review, 65(4): 524-533.

(4) Amponsah, A., Kyei, E. F., Agyemang, J. B., Boakye, H., KyeiDompim, J., Ahoto, C. K., \&Oduro, E. (2020). Nursing-related barriers to children's pain management at selected hospitals in Ghana: a descriptive qualitative study. Pain Research and Management. https://doi.org/10.1155/2020/7125060

(5) Aswathi, V. (2015). A study to assess the effectiveness of local cold application on pain response during intravenous cannula insertion among children (6-12years) admitted in government district headquarters hospital, Namakkal, Tamilnadu (Unpublished Doctoral dissertation, Vivekanandha College of Nursing, Tiruchengode).

(6) Becker, S., Navratilova, E., Nees, F., \& Van Damme, S. (2018). Emotional and motivational pain processing: current state of knowledge and perspectives in translational research. Pain Research and Management; 2 (2): 34-40.

(7) Brusaferro, A., Farinelli, E., Zenzeri, L., Cozzali, R., \& Esposito, S. (2018). The management of pediatric functional abdominal pain disorders: latest evidence. Pediatric Drugs, 20(3), 235-247.

(8) Bukola, I. M., \& Paula, D. (2017). The effectiveness of distraction as procedural pain management technique in pediatric oncology patients: a meta-analysis and systematic review. Journal of Pain and Symptom Management, 54 (4), 589-600.

(9) Drendel, A.l., Kelly, B.T. \& Ali S. (2011). Pain assessment for children: overcoming challenges and optimizing care. Pediatric Emergency Care; 27: 773-781.

(10) Ebrahem, G. G. S., Ahmed, G. E. N., Hammad, A., \&Eid, R. (2019). Applying cryotherapy and balloon inflation technique to reduce pain of arteriovenous fistula cannulation among children undergoing hemodialysis. International Journal of Nursing Didactics, 9(05), 29-35.

(11) Ebrahimpour, F., Pashaeypoor, S., Salisu, W. J., Cheraghi, M. A., \&Hosseini, A. S. (2019). Children's description of pain through drawings and dialogs: A concept analysis. Nursing Open; 6 (2): 301-312.

(12) Egypt Demographics Profile (2017). Available at www.indexmundi.com/egypt/ demographics_profile. Accessed in 26/9/2020.

(13) Egypt Demographics Profile (2020). Available at www.indexmundi.com/egypt/ demographics profile. Accessed in 26/9/2020.

(14) El Geziry, A., Toble, Y., Al Kadhi, F., Pervaiz, M., \& Al Nobani, M. (2018). Non-pharmacological pain management. Pain management in special circumstances, 1-14.

(15) El Said, R., Ouda, W., Mahmoud, F. \& El-Sadek, B. (2017). Effect of cryotherapy on pain intensity at puncture sites of arteriovenous fistula for children undergoing hemodialysis therapy. Unpublished Doctorate Thesis, Faculty of Nursing, Benha University.

(16) Elhalafawy, S. E. H., Bahgat, R. S., Abd-Elhafez, M. A., \&Farag, N. H. (2020). Effect of cryotherapy versus aromatherapy on pain of arteriovenous fistula puncture for children undergoing hemodialysis. IOSR Journal of Nursing and Health Science; 9 (1): 9-19.

(17) Fathalla, A. A., \&Bayoumi, M. H, (2018). Effect of thermomechanical stimulation (buzzy ${ }^{\circledR}$ ) and cryotherapy on children pain, anxiety and satisfaction during blood specimen collection. Journal of Health, Medicine and Nursing, 57, 12-25.

(18) Gaikwad, N. S., Naregal, P. M., Mohite, V. R., \&Karale, R. B. (2017). A Study to Assess the Effectiveness of Ice Application on Pain Response Prior to Intravenous Procedures among Children at Tertiary Care Hospital. Asian journal of pharmaceutical research and health care, 9(4), 167-173. 
(19) Grove, S. K., \& Gray, J. R. (2018). Understanding Nursing Research E-Book: Building an Evidence-Based Practice.7th.ed. Elsevier Health Sciences.

(20) International Association for the Study of Pain (IASP) (2020). Available at www.iasp.pain.org. Accessed on 1-9-2020.

(21) Kahsay, H. (2017). Assessment and treatment of pain in pediatric patients. Current Pediatric Research.; 21 (1): 148-157.

(22) Karlsson, K., Rydstrom, I., Enskar, K. \&Englund, A. (2014). Nurses' perspectives on supporting children during needle-related medical procedures. International Journal of Qualitative Studies in Health and Wellbeing; 9:3, doi: [10.3402/qhw. v9.23063].

(23) Kurian, J. A. (2019). Effect of local cold application on venipuncture site in reducing pain among school age children. International Journal of Research and Review, 6 (8), 545-549.

(24) Levy, N. \& Mills, S. (2018). Pain as the fifth vital sign and dependence on the numerical pain scale is being abandoned in the US: Why. British Journal of Anesthesia; 120 (3):438-435.

(25) McGrath, P. J., Johnson, G., Goodman, J. T., Schillinger, J., \& Dunn, J. (1985). Children's Hospital of Eastern Ontario Pain Scale (CHEOPS). Advanced Pain research and Therapy, 9: 395-402.

(26) Meentken, M., Beynum, I., Legerstee, J., Helbing, W. \&Utens, E. (2017). Medically related post-traumatic stress in children and adolescents with congenital heart defects. Fornteir in Pediatrics. 13. doi: [10.3389/fped.2017.00020]

(27) Pancekauskaitè, G., \&Jankauskaitè, L. (2018). Pediatric pain medicine: pain differences, recognition and coping acute procedural pain in pediatric emergency room. Medicine; 54 (6): 94-100.

(28) Patterson, C., Karuranga, S., Salpea, P., Dahlquist, G., Soltesz, G. \& Ogle, G. (2019). Worldwide estimates of incidence, prevalence and mortality of type 1 diabetes in children and adolescents: results from the international diabetes federation diabetes atlas, 9th edition. Journal of Diabetes and Clinical Practice; September 10, 2019DOI:https://doi.org/10.1016/j.diabres.2019.107842

(29) Roy. M, (2019). Effect of local cold application prior to venipuncture on pain related response among children in selected hospital Burdwan, West Bengal. Journal of Medical Surgical Nursing Practice and Research, 1(2), 6-16. http://doi.org/10.5281/zenodo.3240746.

(30) Santillanes, G. \& Claudius, I. (2015). Pediatric vascular access and blood sampling techniques. Available at www. clinicalgate.com. Accessed on 5/10/2020.

(31) Suraseranivongse, S., Santawat, U., Kraiprasit, K., Petcharatana, S., Prakkamodom, S., \&Muntraporn, N. (2001). Cross $\square$ validation of a composite pain scale for preschool children within 24 hours of surgery. British Journal of Anaesthesia, 87(3), 400-405.

(32) Thrane, S. E., Wanless, S., Cohen, S. M., \&Danford, C. A. (2016). The assessment and non-pharmacologic treatment of procedural pain from infancy to school age through a developmental lens: a synthesis of evidence with recommendations. Journal of Pediatric Nursing; 31(1): e23-e32.

(33) United Nations Educational, Scientific, and Cultural Organization (UNESCO) (2017). Education in rural community. Available at www.un.org.Accessed on 1/9/2020.

(34) Walther-Larsen, S., Pedersen, M. T., Friis, S. M., Aagaard, G. B., Rømsing, J., Jeppesen, E. M., \&Friedrichsdorf, S. J. (2017). Pain prevalence in hospitalized children: a prospective cross $\square$ sectional survey in four Danish university hospitals. Acta Anaesthesiologica Scandinavica, 61(3), 328-337.

(35) Wong, D. \& Baker, C. Wong-Baker FACESR Pain Rating Scale [Internet]. Oklahoma City, Wong-Baker FACES Foundation; 2018. Available from http://wongbakerfaces.org/

(36) World Health Organization. (2020). Diarrhea. Fact sheet No. 331. Available at https://www.who.int/news-room/factsheets/detail/diarrhoeal-disease Accessed at $2 \backslash 10 \backslash 2020$ 